\title{
Modified inside-out transobturator procedure: reply by the authors
}

\author{
Jean de Leval • Alexandre Thomas · David Waltregny
}

Published online: 22 March 2011

(C) The International Urogynecological Association 2011

\section{Dear Editor,}

We thank G.H. Page and A.-S. Page for their interesting comment on our study [1]. In our modified TVT-O technique, the tape is shortened to $12 \mathrm{~cm}$ and the dissection is reduced, the obturator membrane being no longer perforated either by the scissors or by the guide. The rationale for this reduced dissection was to ensure the anchoring of the shortened tape in the obturator membrane and muscles.

Using this modified TVT-O technique, we have observed significantly reduced immediate postoperative groin pain compared with the original TVT-O procedure. As mentioned in the introduction section of our paper, the source of groin pain after transobturator procedures may originate from (1) trauma secondary to the penetration of the dissecting scissors, needles and/or tape into muscular (i.e. obturator and adductor muscles), and/or aponeurotic (i.e. obturator membrane) structures; (2) the foreign body reaction to the tape; (3) possibly owing to proximity to peripheral obturator nerve branches.

From the data we have presented, one cannot identify why the modified TVT-O procedure generates less postoperative groin pain than its original counterpart. We believe this reduced groin pain is likely the result of both the minimized dissection and a lesser inflammatory reaction due to a reduced mesh load. Indeed, it is interesting to note that in the group of patients who had undergone the modified TVT-O procedure, postoperative groin pain scores were variable, thus potentially highlighting individual variability in the acute inflammatory reaction to the shorter tape. In order to evaluate the relative contributions of these two mechanisms, in our trial, we would have needed to include a third arm with patients in whom the original TVT-O tape would have been inserted with minimized dissection (no perforation of the obturator with the scissors/guide). With this in mind, it is legitimate to modify the original TVT-O dissection to a reduced one that no longer includes perforation of the obturator membrane with the scissors/guide.

\section{Reference}

1. de Leval J, Thomas A, Waltregny D (2011) The original versus a modified inside-out transobturator procedure: 1-year results of a prospective randomized trial. Int Urogynecol J 22:145-156. doi:10.1007/s00192-010-1264-4

The comment to which this is a reply can be found at doi:10.1007/ s00192-011-1392-5.

J. de Leval $\cdot$ A. Thomas $\cdot$ D. Waltregny $(\bowtie)$

Department of Urology, University Hospital of Liège,

Central Building, Bat. B35, level -1, CHU Sart Tilman Liège,

4000 Liège, Belgium

e-mail: david.waltregny@ulg.ac.be 